ARTICLE

Received 22 Aug 2014 | Accepted 23 Jan 2015 | Published 3 Mar $2015 \quad$ DOl: 10.1038/ncomms7395

\title{
FAAH genetic variation enhances fronto-amygdala function in mouse and human
}

Iva Dincheva ${ }^{1,2, \star}$, Andrew T. Drysdale ${ }^{3, \star}$, Catherine A. Hartley ${ }^{3, \star}$, David C. Johnson ${ }^{3, \star}$, Deqiang Jing ${ }^{1}$, Elizabeth C. King ${ }^{1,2}$, Stephen Ra1, J. Megan Gray ${ }^{4}$, Ruirong Yang ${ }^{1}$, Ann Marie DeGruccio ${ }^{5}$, Chienchun Huang ${ }^{1}$, Benjamin F. Cravatt ${ }^{6}$, Charles E. Glatt ${ }^{1}$, Matthew N. Hill ${ }^{4}$, B.J. Casey ${ }^{1,2}$ \& Francis S. Lee ${ }^{1,2,3}$

Cross-species studies enable rapid translational discovery and produce the broadest impact when both mechanism and phenotype are consistent across organisms. We developed a knock-in mouse that biologically recapitulates a common human mutation in the gene for fatty acid amide hydrolase (FAAH) (C385A; rs324420), the primary catabolic enzyme for the endocannabinoid anandamide. This common polymorphism impacts the expression and activity of FAAH, thereby increasing anandamide levels. Here, we show that the genetic knock-in mouse and human variant allele carriers exhibit parallel alterations in biochemisty, neurocircuitry and behaviour. Specifically, there is reduced FAAH expression associated with the variant allele that selectively enhances fronto-amygdala connectivity and fear extinction learning, and decreases anxiety-like behaviours. These results suggest a gain of function in fear regulation and may indicate for whom and for what anxiety symptoms FAAH inhibitors or exposure-based therapies will be most efficacious, bridging an important translational gap between the mouse and human.

\footnotetext{
${ }^{1}$ Department of Psychiatry, Weill Cornell Medical College of Cornell University, 1300 York Avenue, New York, New York 10065, USA. ${ }^{2}$ Department of Pharmacology, Weill Cornell Medical College of Cornell University, 1300 York Avenue, New York, New York 10065, USA. ${ }^{3}$ Sackler Institute for Developmental Psychobiology, Weill Cornell Medical College of Cornell University, 1300 York Avenue, New York, New York 10065, USA. ${ }^{4}$ Hotchkiss Brain Institute and Mathison Centre for Mental Health Research and Education, Departments of Cell Biology and Anatomy \& Psychiatry, University of Calgary, 3330 Hospital Drive NW, Calgary AB Canada T2N4N1. ${ }^{5}$ in Genious Targeting Laboratory, 2200 Smithtown Avenue, Ronkonkoma, New York 11779, USA. ${ }^{6}$ Department of Chemical Physiology, The Scripps Research Institute, 10550 North Torrey Pines Road, La Jolla, California 92037, USA. * These authors contributed equally to this work. Correspondence and requests for materials should be addressed to B.J.C. (email: bjc2002@med.cornell.edu) or to F.S.L. (email: fslee@med.cornell.edu).
} 
T ranslational research holds the promise to leverage basic scientific findings into advances for human health. Studies in animal models play an important role in this process, enabling the precise delineation of the mechanisms underlying behaviour in humans, in whom such fine-scale resolution is difficult to achieve. A critical requirement for the success of this translational approach is that the phenotypes of interest are consistent across species. In the present study, we show that a single-nucleotide polymorphism (SNP) in the fatty acid amide hydrolase $(F A A H)$ gene of the endocannabinoid system has parallel molecular, neural and behavioural effects in both humans and mice engineered to express the variant human allele, filling an important translational gap.

The endocannabinoid system has been implicated in human anxiety ${ }^{1-3}$. Anandamide (AEA), an endogenous cannabinoid $(\mathrm{eCB})$ agonist at the $\mathrm{CB}_{1}$ receptor, is proposed to play a central role in this effect ${ }^{2,4}$. FAAH is a catabolic enzyme and primary regulator of AEA signalling in the brain ${ }^{5}$. In humans, differential expression of FAAH protein is associated with a common SNP (C385A; rs324420) of which $\sim 38 \%$ of individuals of European descent are carriers (AC and AA genotypes) ${ }^{6}$. This polymorphism leads to the substitution of an evolutionarily conserved proline at amino-acid position 129 with a threonine residue, which in turn renders the FAAH protein more vulnerable to proteolytic degradation. Accordingly, the FAAH C385A SNP enhances eCB signalling by reducing steady-state levels of FAAH protein, which leads to elevated AEA levels ${ }^{7-9}$. Pharmacologic manipulations and genetic knockout of $F A A H$ have been implicated in anxiolytic behaviours including enhanced fear extinction learning $2,10,11$. However, the ability to characterize the effects of the FAAH variant in the brain has been limited, since the variant is only present in humans. Here, we describe the development of a knock-in mouse that expresses the variant A (threonine) allele of the $F A A H$ polymorphism in place of the conserved ancestral C (proline) allele, enabling the demonstration of parallel molecular, circuit-level and behavioural phenotypes in humans and in the knock-in mice carrying this variant.

\section{Results}

Generation and validation of FAAH C385A knock-in mice. We examined molecular and biochemical effects in the FAAH knock-in mouse to determine whether they paralleled effects of the human SNP (Fig. 1a,b). Specifically, human carriers of the A-allele have been shown to have reduced FAAH protein levels in their lymphocytes due to protein-folding abnormalities and increased proteolytic breakdown, leading to elevated plasma levels of $\mathrm{AEA}^{7-9}$. A fundamental question has been whether these alterations observed in peripheral tissues reflect parallel modulation of the eCB system by this SNP in the brain. In the FAAH knock-in mouse, analysis of relative protein expression levels in the forebrain showed a main effect of genotype on FAAH protein levels (analysis of variance (ANOVA) with post hoc Dunnett's test $(F(2,6)=8.96, P<0.02))$ with an allele dosedependent decrease in FAAH levels among knock-in mutants (Fig. 1c; Supplementary Fig. 1). There was also a main effect of genotype on FAAH hydrolytic activity (ANOVA with post hoc Dunnett's test $(\mathrm{F}(2,12)=7.89 P<0.01))$ (Fig. 1d) and AEA levels (ANOVA with post hoc Dunnett's test $(\mathrm{F}(2,11)=7.25, P<0.02)$ ) (Fig. 1e), but not for the levels of the endocannabinoid, 2-arachidonoylglycerol (2-AG), which is not a FAAH substrate (Supplementary Fig. 2). There was also no genotypic effect on the maximal binding site density for the $\mathrm{CB}_{1}$ receptor
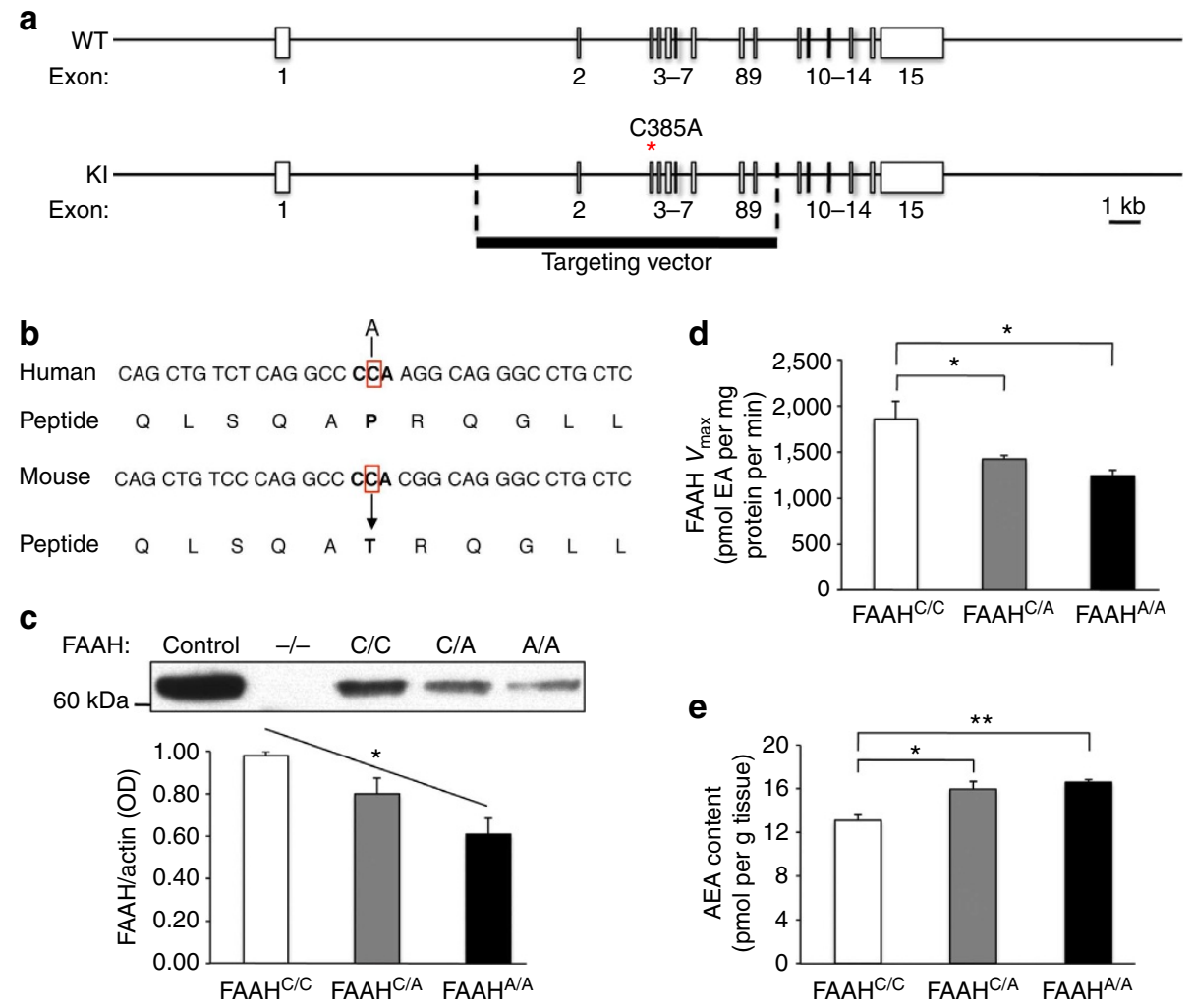

Figure 1 | Generation and validation of FAAH C385A knock-in mice. (a) A portion of the coding region in the FAAH gene is replaced with C385A SNP. (b) The region encompassing the SNP has high homology between human and mouse FAAH genes. (c) FAAH protein levels in knock-in mice $\left(\mathrm{FAAH} \mathrm{H}^{\mathrm{C} / \mathrm{A}} ; \mathrm{FAAH}^{\mathrm{A} / \mathrm{A}}\right.$ ) and wild-type $\left(\mathrm{FAAH} \mathrm{H}^{\mathrm{C} / \mathrm{C}}\right.$ ) littermates from three independent western blot analyses. Brain homogenates from $\mathrm{FAAH} \mathrm{H}^{-/-}$mice, and lysates from heterologous 293 cells overexpressing $F A A H$, were used as controls. (d) FAAH hydrolytic activity and (e) anandamide (AEA) content in FAAH knock-in mouse forebrain homogenates ( $n=4$ per group). (EA; ethanolamine). Means \pm s.e.m. presented. ${ }^{\star} P<0.05,{ }^{\star \star} P<0.01$. 
a

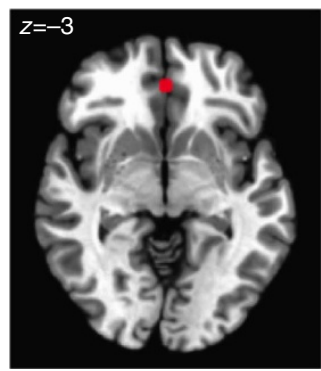

b

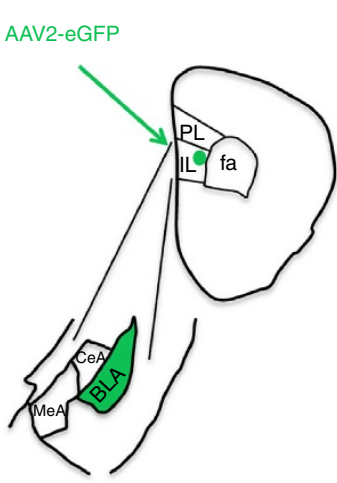

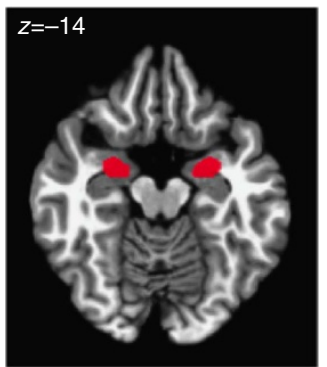

$\mathrm{FAAH}^{\mathrm{C} / \mathrm{C}}$
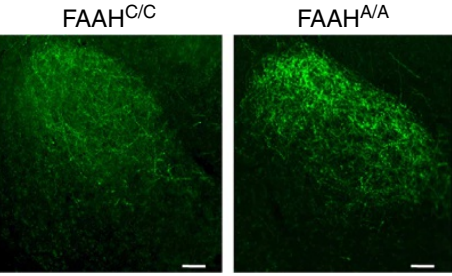

$\star \star \star$

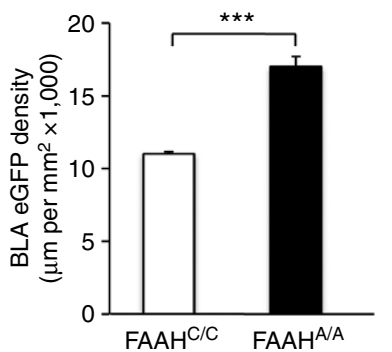

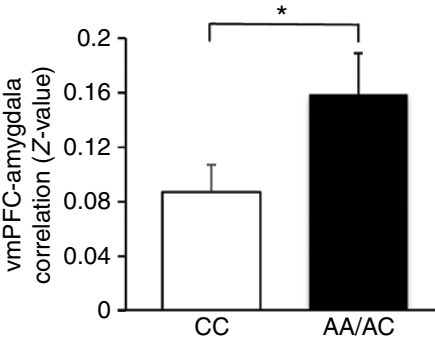

c
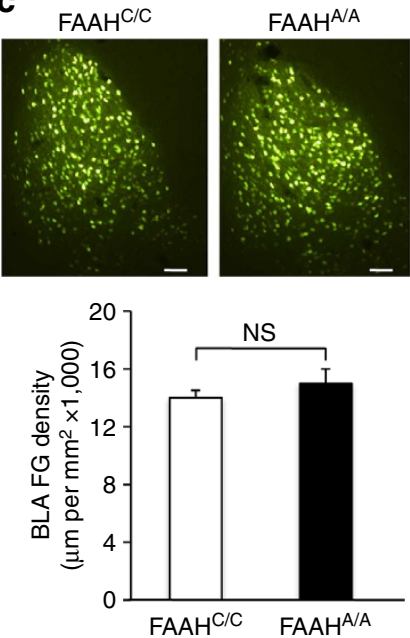

Figure 2 | Functional and structural connectivity between ventromedial prefrontal cortex (vmPFC) and amygdala in humans and mice with FAAH C385A. (a) fMRI functional connectivity compared between subgenual vmPFC ( $x, y, z=0,40,-3)$ and bilateral amygdala in A-allele carriers ( $n=17$ ) relative to $C$ homozygotes $(n=18)$. (b) Anterograde tracer (AAV2-eGFP; eGFP), targeted to IL, labelled afferents in BLA in FAAHA/A mice $(n=4)$ and controls (FAAH $\left.{ }^{\mathrm{C} / \mathrm{C}} ; n=4\right)$. Drawing illustrates anatomical boundaries. (c) Retrograde tracer (fluorogold; FG), targeted to IL, labelled BLA cell bodies in FAAH ${ }^{\mathrm{A} / \mathrm{A}}$ mice $(n=4)$ and controls $\left(F A A H^{\mathrm{C} / \mathrm{C}} ; n=4\right)$. (Scale bars, $100 \mu \mathrm{m}$.) Means \pm s.e.m. presented. ${ }^{\star} P<0.05,{ }^{\star \star \star} P<0.001$. NS, not significant.

(Supplementary Fig. 3). This mouse model provides the first demonstration of biochemical changes within the brain due to the FAAH C385A SNP and mirrors its reported effects in human lymphocytes. These findings validate that the FAAH C385A knock-in mouse recapitulates the known molecular and biochemical phenotypes of the human FAAH C385A polymorphism, supporting its use as a model of higher-level neural and behavioural phenotypes.

Enhanced fronto-amygdala connectivity in humans and mice. We tested for cross-species translation in genotypic effects of $F A A H$ on fronto-amygdala circuitry and function in mice and humans with the variant A-allele. In humans, FAAH C385A has been associated with variation in reactivity to threat ${ }^{1}$. However, it is unclear how the FAAH C385A polymorphism might alter the circuitry implicated in this behavioural domain. Fearconditioning studies in animal models suggest that dynamic interaction between the amygdala and two subregions of the prefrontal cortex (PFC) can drive opposing behavioural responses to threat ${ }^{12-15}$. Whereas the prelimbic (PL) region promotes fear expression, the infralimbic (IL) region constrains the regulation of threat responses. Neuroimaging studies examining correlates of these opposing behaviours in humans suggest that a dorsal anterior cingulate cortex (ACC) region exhibits functional parallels to rodent $\mathrm{PL}$, and a subgenual region of ventromedial PFC (vmPFC) exhibits functional parallels to rodent $\mathrm{IL}^{16-19}$.

We performed species-specific connectivity analyses focusing on key regions within the fronto-amygdala circuitry that regulate fear responses and fear extinction learning. First, we examined resting-state connectivity between the subgenual vmPFC and amygdala and the dorsal ACC and amygdala in humans by genotype. A-allele carriers (Supplementary Table 1) showed increased correlations between the blood oxygen level-dependent signals in the vmPFC and the bilateral amygdala $(t(34)=2.71$, $P=0.037$ ) (Fig. 2a; Supplementary Fig. 4a; Bayesian statistical analysis in Supplementary Fig. 5a). This pattern was selective to subgenual vmPFC-amygdala connectivity, with no genotypic difference in dorsal ACC-amygdala connectivity (Supplementary Fig. 6a). A substantial literature suggests that stronger inverse functional connectivity between the vmPFC and the amygdala during emotion-related tasks is associated with decreased anxiety or negative emotion ${ }^{20-22}$. In contrast, positive restingstate functional connectivity between these regions has been associated with lower anxiety ${ }^{23-25}$. Our present finding is consistent with this broader literature suggesting that greater positive corticoamygdala connectivity at rest predicts more effective emotional control ${ }^{23,26}$.

To delineate the precise location and directionality of genotypic differences in fronto-amygdala circuitry, we used anterograde (adeno-associated virus 2 expressing enhanced green fluorescent protein; AAV2-eGFP) and retrograde (fluorogold (FG)) tracers in our FAAH knock-in mouse. These tract-tracing experiments revealed increased projections from IL to basolateral amygdala (BLA) in mice (FAAH ${ }^{\mathrm{A} / \mathrm{A}}>\mathrm{FAAH}^{\mathrm{C} / \mathrm{C}}$; two-tailed Student's $t$-test, $P<0.001)$, but no genotypic differences in ascending projections from BLA to IL $\left(\mathrm{FAAH}^{\mathrm{A} / \mathrm{A}}>\mathrm{FAAH}^{\mathrm{C} / \mathrm{C}}\right.$; two-tailed Student's $t$-test, $P>0.56$ ) (Fig. 2b,c). Mirroring the human imaging findings, we found no genotypic differences in descending or ascending projections between the PL and BLA in the mouse 


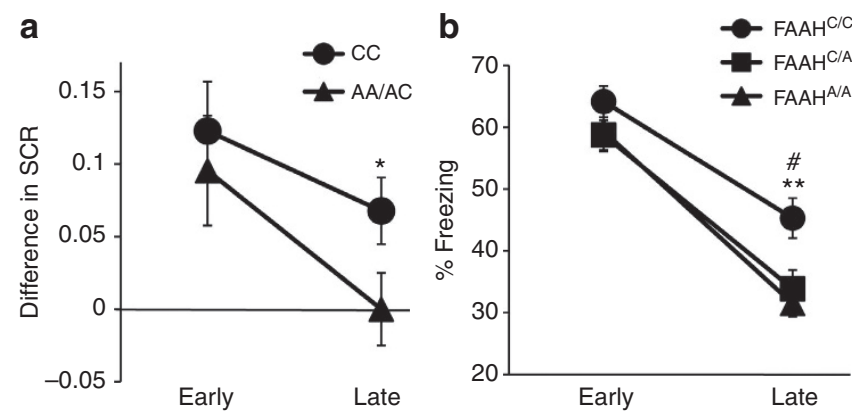

Figure 3 | Enhanced cued fear extinction in humans and mice with FAAH C385A. (a) Extinction, indexed by differential skin conductance response (SCR) (CS +-CS - ), in 18 A-allele carriers and $22 \mathrm{C}$ homozygotes. Trials were binned into early (average of the first five trials) and late (average of the following six trials). (b) Fear extinction, time spent freezing to cue, was tested in wild-type (FAAH $\left.{ }^{\mathrm{C} / \mathrm{C}} ; n=21\right)$, heterozygous

$\left(\right.$ FAAH $\left.{ }^{C / A} ; n=20\right)$ and homozygous knock-in mice $\left(F A A H^{A / A} ; n=20\right)$. Extinction trials were binned into early (average of extinction day 1 ) and late trials (average of extinction day 4 ). Means \pm s.e.m. presented. ${ }^{\star} P<0.05$,

${ }^{\#} P<0.05$ heterozygous knock-in mice versus wild-type controls, ${ }^{\star \star} P<0.01$ homozygous knock-in mice versus wild-type controls.

(Supplementary Fig. 6a-c). Selective increases in descending IL-amygdala projections offer a structural neuroanatomical basis for the increased functional connectivity in fronto-amygdala circuitry in human A-allele carriers and may help explain reported genotypic differences in emotion regulation ${ }^{1}$.

Enhanced cued fear extinction in humans and mice. Building on our biochemical and circuit-level genotypic differences in mice and humans, we tested for behavioural effects of this variation across species in parallel fear extinction experiments. The selective increase in connectivity within an established fear regulatory circuit (IL-BLA projection) in the mouse and the homologous vmPFC-amygdala circuit in human, led to the $a$ priori prediction that A-allele carriers would show improved fear extinction learning but no difference in fear acquisition. These predictions are consistent with reported effects of pharmacological and genetic knockout manipulations of FAAH expression in mice e $^{2,27,28}$. We tested humans (22 CC-alleles, 18A-allele carriers; Supplementary Table 2) and mice using cued fear conditioning with extinction on the following day. In humans, there was no main effect of the FAAH genotype on fear acquisition (Supplementary Fig. 7a), but there was an effect of the genotype on fear extinction. Namely, human A-allele carriers exhibited facilitated fear extinction learning, as indexed by decreased galvanic skin responses during late trials of extinction training $(\mathrm{F}(1,36)=4.35, P=0.044)$, controlling for age and gender effects between genotypic groups (Fig. 3a; Supplementary Fig. 4b; Bayesian statistical analysis in Supplementary Fig. 5b). Parallel findings in mice showed a significant effect of genotype on freezing behaviour during extinction (ANOVA with post hoc Bonferroni test $(\mathrm{F}(2,116)=6.8, \quad P<0.01)) \quad($ Fig. $\quad 3 b)$, with heterozygous $(P<0.05)$ and homozygous $(P<0.01)$ FAAH C385A mice showing less freezing behaviour compared with wild types in late trials, but no difference in early trials (Fig. 3b) or in fear acquisition (Supplementary Fig. 7b). These parallel effects of enhanced fear extinction in FAAH A-allele carriers have not previously been established for both mice and humans.

Decreased anxiety levels in humans and mice. We further characterized the anxiolytic phenotype of the FAAH variant
A-allele in both mice and humans using standard measures of anxiety-related behaviours. Given that our results demonstrated enhanced fear extinction in human and mouse FAAH A-allele carriers, we predicted they would also show reduced anxiety ${ }^{1,2,10,27-29}$. In 137 humans (Supplementary Table 3), A-allele carriers reported reduced levels of trait anxiety $(t(135)=2.30, \quad P=0.019) \quad$ (Fig. 4a; Supplementary Fig. 4c; Bayesian statistical analysis in Supplementary Fig. 5c); this effect was replicated in our separate fear extinction cohort (Supplementary Table 2; Supplementary Fig. 8). In mice, we performed two standard measures of anxiety-like behaviours that involve placing subjects in conflict situations. In the elevated plus maze (EPM) test, homozygous mutant mice spent a higher percentage of time in the open arms than wild-type controls (ANOVA with post hoc Dunnett's test $(\mathrm{F}(2,37)=2.89, P<0.04)$ ), indicative of reduced anxiety-like behaviour (Fig. 4b). There was no significant difference in total distance travelled (Supplementary Fig. 9). In the novelty-induced hypophagia (NIH) task, mice were trained to approach a reward (sweetened milk) in their home cage and then tested in a novel, brightly lit environment. For this task, the latency to approach and drink the sweetened milk in the novel environment is a measure of anxietyrelated behaviour ${ }^{30}$. FAAH C385A mice showed decreased latency to drink milk in the NIH task, suggesting decreased anxiety phenotype (ANOVA with post hoc Dunnett's test $(\mathrm{F}(2,44)=5.83, P<0.01)$ ) (Fig. 4c). To investigate the neural correlates of the observed anxiolytic effects, we examined neural activity, as indicated by expression of the early immediate gene $c$-Fos ${ }^{31}$, in the BLA following the NIH task. We found a main effect of genotype on BLA c-Fos expression in mutant knock-in mice (ANOVA with post hoc Dunnett's test $(\mathrm{F}(2,15)=53.92$, $P<0.0001))$ in a dose-dependent pattern, suggesting decreased engagement of the BLA in these mice during a stressful experience (Fig. $4 \mathrm{~d}$ ). This reduced activation of the amygdala in response to stressful situations is consistent with reductions in amygdala activity in response to threat in human FAAH A-allele carriers ${ }^{1}$.

\section{Discussion}

Using a vertically integrated approach with parallel studies in humans and mice, we have identified the relevance and impact of the FAAH C385A polymorphism on brain biochemistry, neurocircuitry, behaviour and symptoms. We validate our mouse model by showing that the FAAH variant allele leads to reductions in FAAH protein and enzymatic activity and increases in AEA levels in the brain. Our subsequent analyses in humans and mice elucidated circuit level and behavioural phenotypes not previously established in human carriers of this variant. We found enhanced fear extinction in both humans and mice with the C385A mutation. In addition, our finding of selectively enhanced fronto-amygdala connectivity in both mouse and human A-allele carriers provides a mechanistic explanation for these behavioural effects through enhanced regulation of BLA responses to threat by the IL. Non-replication of candidate gene association studies has been a major problem within the field of behavioural genetics. Here, we have used a parallel mouse-human experimental approach that enables greater control for environmental and genetic confounds. The convergent findings reported here establish that effects of genetic variation in FAAH are evident at neural and behavioural levels in both the mouse and in humans, providing a persuasive cross-species validation. Thus, this variant SNP may represent a gain of function in the domain of anxiety-related behaviours and may prove valuable in determining for whom and for what symptoms FAAH inhibitors or exposure-based therapies, which build on basic principles of 
a

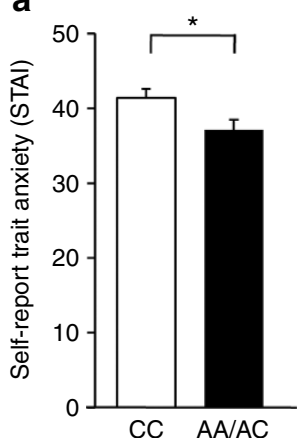

b

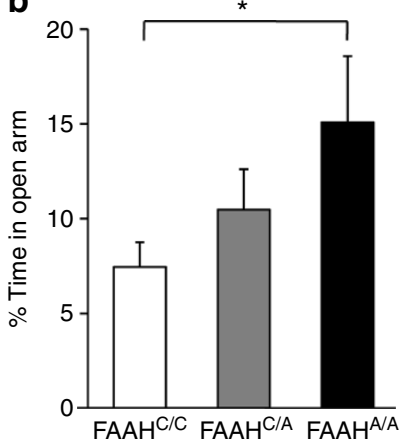

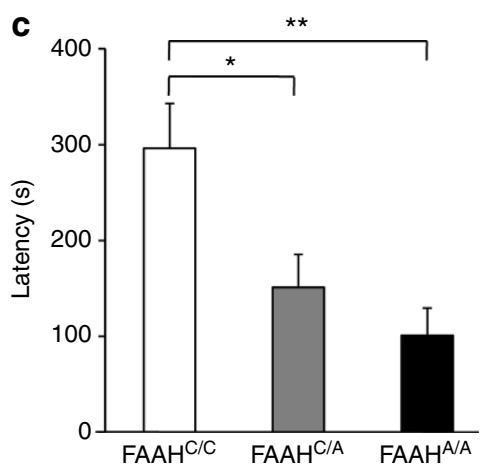
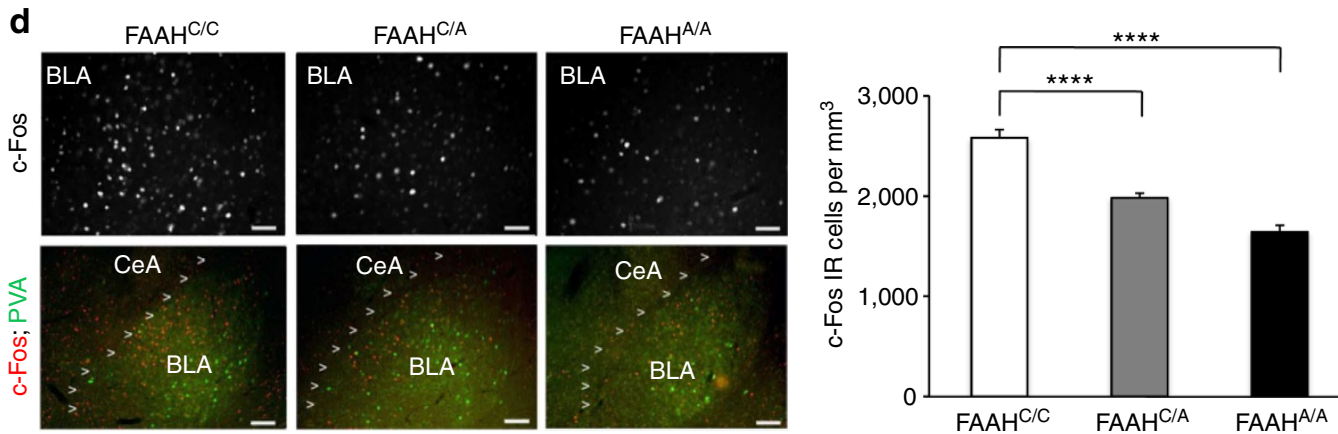

Figure 4 | Decreased anxiety in humans and mice with FAAH C385A. (a) Trait anxiety levels in A-allele carriers $(n=57)$ and C homozygotes $(n=80)$. Anxiety-related behaviour in FAAH C385A mice in (b) elevated plus maze (FAAH ${ }^{\mathrm{C} / \mathrm{C}}, n=17$; FAAH $\mathrm{C} / \mathrm{A}, n=11 ; \mathrm{FAAH} \mathrm{H}^{\mathrm{A} / \mathrm{A}}, n=12$ ) and (c) novelty-induced hypophagia (NIH) (FAAH $\left.{ }^{C / C}, n=16 ; F^{2} A^{C / A}, n=21 ; F A A H^{A / A}, n=10\right)$. (d) Photomicrographs of NIH-induced c-Fos (red) labelling in the BLA (parvalbumin (green)) in FAAH C385A mice. Density of c-Fos immunoreactive (IR) cells in BLA, $n=5$ per group. (Scale bars. $50 \mu \mathrm{m}$ upper row, $100 \mu \mathrm{m}$ lower row.) Means \pm s.e.m. presented. ${ }^{\star} P<0.05,{ }^{\star \star} P<0.01,{ }^{\star \star \star \star} P<0.0001$

extinction learning, will be most efficacious. In this way, therapeutics might be tailored to an individual to move from standard care to more precise personalized care. A persistent problem identified in animal models of disease is a failure of the findings to translate to the human in clinical trials. Our studies translate mouse behavioural and brain findings to show their human relevance using parallel paradigms and imaging tools across species. Thus, the present results obtained using this integrated approach bridge a large translational gap from mouse to human.

\section{Methods}

Generation of FAAH C385A mice. The replacement-targeting vector consisted of a $9.53-\mathrm{kb}$ mouse genomic fragment containing exons 2-9 FAAH-coding sequence. In a 1.6 -kb fragment containing the $F A A H$-coding region, the $\mathrm{C} 385 \mathrm{~A}$ mutation was introduced and put back into the targeting vector. The flippase recognition target Neo cassette was introduced via homologous recombination as a positive selection marker. A pGK-thymidine kinase cassette was used as a negative selection marker. The targeting vector was comprised of a $1.88-\mathrm{kb}$ short arm, a $5.52-\mathrm{kb}$ long arm, a 9.53-kb targeted sequence carrying the C385A mutation and the Neo cassette flanked by two flippase recognition target sites. Linearalized targeting vectors were electroporated into iTL BA1 $(\mathrm{C} 57 \mathrm{BL} / 6 \mathrm{~N} \times 129 / \mathrm{SvEv})$ hybrid embryonic stem cells. DNA derived by G418-resistant embyonic stem cell clones were screened using a diagnostic SspI and BamHI restriction enzyme digestions. Recombinant clones containing the predicted 8.6 - and $10.4-\mathrm{kb}$ rearranged bands were obtained at a frequency of 5 in 100 . Two positive embryonic stem cell clones were injected into C57BL/ 6 blastocysts, which were then introduced into pseudopregnant females. Chimeric animals were mated with $\mathrm{C} 57 \mathrm{BL} / 6$ to produce heterozygous animals, and these mice were subsequently crossed with C57LB/6 mice expressing FLP recombinase in germ cells to excise the neo cassette. Upon weaning, all genotypes were housed together and randomly assigned to experimental groups. Sample size was chosen based on previous literature for each experimental procedure. All analyses were performed on mice back-crossed at least seven generations onto the C57BL/6 genetic background.

Western Blot analysis. Samples of brain lysates were prepared as described previously $^{32}$. Briefly, brain tissue was incubated in RIPA lysis buffer $(150 \mathrm{mM} \mathrm{NaCl}$, $50 \mathrm{mM}$ Tris $\mathrm{pH} 8,5 \mathrm{mM}$ EDTA, $1 \%$ Triton X-100, 0.5\% sodium deoxycholate and
$0.1 \%$ sodium dodecyl sulphate) with protease and phosphatase inhibitors (1:100, Calbiochem \#539131 and \#524625, respectively). Samples were triturated, rotated at $4{ }^{\circ} \mathrm{C}$ for $30 \mathrm{~min}$ then spun down at 14,000 r.p.m. for $10 \mathrm{~min}$ at $4{ }^{\circ} \mathrm{C}$. The supernatant was collected and cell debris discarded. Protein concentration was measured using a BCA kit. To measure FAAH levels, $10 \mathrm{mg}$ of forebrain lysate was resolved by SDSPAGE electrophoresis (NuPAGE 10\% Bis-Tris gel; Invitrogen \#NP0315) and probed with antibodies: mouse monoclonal anti-FAAH (Abcam, ab54615; 1:500) and goat polyclonal anti-actin (Santa Cruz, sc-1616HRP; 1:5,000) were used. As a positive control, 293T cells purchased from American Type Culture Collection were transfected with $1 \mathrm{mg}$ mouse FAAH complementaryDNA clone (Origene, NM_010173), and lysates were processed in parallel. Forebrain lysate from FAAH knockout mice ${ }^{5}$ were used as a negative control.

FAAH activity assay. FAAH activity from forebrain lysates was measured as the conversion of AEA labelled with $\left[{ }^{3} \mathrm{H}\right]$ in the ethanolamine portion of the molecule $\left(\left[{ }^{3} \mathrm{H}\right] \mathrm{AEA}\right)$ to $\left[{ }^{3} \mathrm{H}\right]$ ethanolamine, as reported previously ${ }^{33}$. Membranes were incubated in a final volume of $0.5 \mathrm{ml}$ of TME buffer $(50 \mathrm{mM}$ Tris- $\mathrm{HCl}, 3.0 \mathrm{mM}$ $\mathrm{MgCl}_{2}$ and $1.0 \mathrm{mM}$ EDTA, $\mathrm{pH} 7.4$ ) containing $1.0 \mathrm{mg} \mathrm{ml}^{-1}$ fatty acid-free bovine serum albumin (BSA) and $0.2 \mathrm{nM}\left[{ }^{3} \mathrm{H}\right] \mathrm{AEA}$. Isotherms were constructed using eight concentrations of AEA at concentrations between $10 \mathrm{nM}$ and $10 \mu \mathrm{M}$. Incubations were carried out at $37^{\circ} \mathrm{C}$ and were stopped with the addition of $2 \mathrm{ml}$ of chloroform/methanol (1:2). After standing at ambient temperature for $30 \mathrm{~min}$, $0.67 \mathrm{ml}$ of chloroform and $0.6 \mathrm{ml}$ of water were added. Aqueous and organic phases were separated by centrifugation at 1,000 r.p.m. for $10 \mathrm{~min}$. The amount of $\left[{ }^{3} \mathrm{H}\right]$ in $1 \mathrm{ml}$ of the aqueous phase was determined by liquid scintillation counting and the conversion of $\left[{ }^{3} \mathrm{H}\right]$ AEA to $\left[{ }^{3} \mathrm{H}\right]$ ethanolamine was calculated. The $V_{\max }$ values for this conversion were determined by fitting the data to a single-site competition equation using Prism.

Lipid extraction from tissue for eCB levels. For analysis of endocannabinoid content, brain regions were subjected to a lipid extraction process. Forebrain tissue samples were weighed and placed into borosilicate glass culture tubes containing $2 \mathrm{ml}$ of acetonitrile with $5 \mathrm{pmol}$ of $\left[{ }^{2} \mathrm{H}_{8}\right]$ anandamide and $5 \mathrm{nmol}$ of $\left[{ }^{2} \mathrm{H}_{8}\right] 2$-arachidonoylglycerol for extraction. Tissue was homogenized with a glass rod and sonicated for $30 \mathrm{~min}$ on ice. Samples were incubated overnight at $-20^{\circ} \mathrm{C}$ to precipitate proteins then centrifuged at $1,500 \mathrm{~g}$ to remove particulates. The supernatants were removed to a new glass tube and evaporated to dryness under $\mathrm{N}_{2}$ gas. The samples were resuspended in $300 \mu \mathrm{l}$ of acetonitrile to recapture any lipids adhering to the glass tube, and dried again under $\mathrm{N}_{2}$ gas. Finally, lipid extracts were suspended in $20 \mu \mathrm{l}$ of acetonitrile, and stored at $-80^{\circ} \mathrm{C}$ until analysis 
Mass spectrometrical detection of eCBs. Liquid chromatography-mass spectrometry (LC-MS/MS) analyses were carried out on an Eksigent ekspert micro LC 200 coupled with an AB Sciex Qtrap 5500 mass spectrometer, installed with a Turbo V Spray ion source (AB Sciex, Canada). The LC was equipped with a temperature-controlled CTC autosampler. An Eksigent HALO C18 HPLC column $(1 \times 50 \mathrm{~mm}, 2.7 \mu \mathrm{m}$ particle diameter, $90 \AA$ A pore size $)$ was used. Samples were analysed isocratically, at a flow rate of $30 \mu \mathrm{lmin}-1$, and a solvent composition of $15 \%$ mobile phase $\mathrm{A}(10 \mathrm{mM}$ ammonium acetate in water) and $85 \%$ mobile phase B (acetonitrile). After $3.25 \mathrm{~min}$, the column was regenerated with $100 \%$ B. Before each injection, the column was re-equilibrated at the initial mobile phase condition for $2 \mathrm{~min}$. Following each LC-MS/MS run, a blank was run. The sample injection loop ( $5 \mu \mathrm{l}$ loop size) was rinsed with $40 \mu \mathrm{l}$ of methanol, and the column purged for $5 \mathrm{~min}$ with $100 \% \mathrm{~B}$ for $4.5 \mathrm{~min}$ and followed by $85 \%$ B for $0.5 \mathrm{~min}$. This was intended to mitigate cross contaminations due to carryover from preceding sample injections. The $\mathrm{LC}$ column was maintained at $25^{\circ} \mathrm{C}$, and the samples at $10^{\circ} \mathrm{C}$.

The mass spectrometer was operated in positive ion mode, with the ion-spray voltage set at 5,500 V, curtain gas at 20 (a.u.), source gas 1 and gas 2 both at 40 (a.u.), and source temperature at $300^{\circ} \mathrm{C}$. Protonated molecular ions of AEA $(\mathrm{m} / \mathrm{z}$ $348)$ and AEA-d8 $(\mathrm{m} / \mathrm{z} 356)$, and ammonium adduct ions of 2-AG $(\mathrm{m} / \mathrm{z} 396)$ and 2-AG-d8 $(\mathrm{m} / z$ 404) were selected as the respective precursor ions for collision induced dissociation (CID). Multiple reaction monitoring (MRM) scan modes were used with Q1 and Q3 both at unit resolution. Optimized collision energies for the transitions were as follows: AEA (348 to 62) CE $22 \mathrm{~V}$, AEA-d8 (356 to 62) CE $22 \mathrm{~V}$, 2-AG (396 to 287) CE $15 \mathrm{~V}$ and 2-AG-d8 (404 to 294) CE $17 \mathrm{~V}$.

Each brain tissue extract sample was further diluted in acetonitrile to yield a 100-fold diluted sample, for the LC-MS/MS quantification of 2-AG, while the undiluted extract sample was analysed directly for quantification of AEA. It has been reported that 2-AG undergoes spontaneous isomerization converting to 1-AG by acyl group migration during tissue extraction and reconstitution procedures. We also observed that 1-AG was present in authentic standard solutions of 2-AG, as well as brain tissue extracts. Peak areas of 1-AG and 2-AG were combined to establish a standard calibration curve for 2-AG. The data processing was accomplished using Analyst 1.5.2 software (AB Sciex). Linear regressions of relative peak areas (analyte to internal standard ratios) were performed over analyte concentrations from 0.00025 to $0.25 \mathrm{pmol}_{\mu 1}^{-1}$ (AEA), and 0.0025 to $2.5 \mathrm{pmol}^{-1} \mathrm{l}^{-1}$ (2-AG). Analyte levels were normalized to tissue weight.

\section{$\mathrm{CB}_{1}$ receptor-binding assay. $\mathrm{CB}_{1}$ receptor agonist-binding parameters were} determined using radioligand binding using a Multiscreen Filtration System with Durapore 1.2-lM filters in 96-well filter plates (Millipore, USA) through a protocol previously described ${ }^{34}$. Incubations (total volume $=0.2 \mathrm{ml}$ ) were carried out using TME buffer containing $1 \mathrm{mg} \mathrm{ml}^{-1}$ BSA (TME/BSA). Membranes (10 $\mu \mathrm{g}$ protein per incubate) were added in triplicate to wells containing $0.1,0.25,0.5,1.0,1.5$ or $2.5 \mathrm{nM}[3 \mathrm{H}] \mathrm{CP} 55,940$ (American Radiochemicals, USA), a cannabinoid $\mathrm{CB}_{1}$ receptor agonist, and incubated for $1 \mathrm{~h}$ at room temperature on an orbital shaker. Ten micromolar AM251 (Tocris Biosciences, USA) was used to determine nonspecific binding. $B_{\max }$ (maximal binding site density) values were determined by nonlinear curve fitting of specific binding data to the single site-binding equation using GraphPad Prism (GraphPad, USA).

Behavioural overview. To reduce experimental variability, age-matched littermate pairs resulting from heterozygous crossings were randomly assigned to experimental groups. Only adult male mice were used for all experiments. All behavioural measurements were performed by observers blind to genotype. All animals were kept on a $12: 12$ light-dark cycle at $18{ }^{\circ} \mathrm{C} \sim 22^{\circ} \mathrm{C}$ with food and water available ad libitum unless noted otherwise. All procedures were in accordance with the NIH Guide for the Care and Use of Laboratory Animals and were approved by the Institutional Animal Care and Use Committee of Weill Cornell Medical College.

Cued fear-conditioning and extinction procedure. The task was conducted as described previously ${ }^{35}$. Briefly, the fear-conditioning apparatus consisted of a mouse shock-chamber (Coulbourn Instruments, USA) placed in a soundattenuated box. On day 1 (acquisition), after a 2-min acclimation period to the conditioning chamber (scented with $0.1 \%$ peppermint in $70 \% \mathrm{EtOH}$ ), mice were fear conditioned with three tone-shock pairings, consisting of a 30-s presentation of a tone (conditioned stimulus; $5 \mathrm{kHz}, 70 \mathrm{~dB}$ ) that coterminated with a $0.7-\mathrm{mA}$ foot shock (unconditioned stimulus) during the last $1.0 \mathrm{~s}$ of the tone with an intertrial interval of $30 \mathrm{~s}$. Mice remained in the conditioning chamber for $1 \mathrm{~min}$ before being returned to their home cages. Twenty-four hours after fear acquisition, mice were exposed to five presentations of the tone in the absence of shock (extinction). To eliminate any confounding interactions of contextual fear, tones were presented in a novel context, consisting of a white cylindrical arena (scented with $0.1 \%$ lemon in $70 \% \mathrm{EtOH}$ ). Tone presentations lasted for $30 \mathrm{~s}$ with an intertrial interval of $30 \mathrm{~s}$. After the final tone presentation, mice remained in the conditioning chamber for $1 \mathrm{~min}$ before being returned to their home cages. Fear extinction trials were repeated daily for a total of 4 days of extinction training. Graphic State 3.02 software was used to control experiments. Mice were videotaped for subsequent analysis. Freezing was defined as the absence of visible movement except that required for respiration ${ }^{36}$. The percentage time spent freezing was calculated by dividing the amount of time spent freezing during the 30 -s tone presentations by the duration of the tone.

EPM procedure. The EPM task was conducted as described previously ${ }^{37}$. The maze was constructed of grey Plexiglas, raised $70 \mathrm{~cm}$ above the floor and consisted of two opposite closed arms with 14-cm-high opaque walls and two opposite open arms of the same size $(29 \mathrm{~cm} \times 6 \mathrm{~cm})$. The maze was set up under a digital camera connected to a video recorder and computer under the control of Ethovision XT 5.0 software (Noldus, USA) to live track subject movements. A single testing session of 10 min was carried out under dim light ( $\sim 6$ Lux in centre of maze). To begin a trial, the animal was placed in the centre of the maze facing an open arm. The maze was cleaned with a $70 \%$ ethanol solution between trials to eliminate possible odour cues left by previous subjects. Measures of anxiety-like behaviour were assessed by calculating the percentage time spent in the open arms by dividing the amount of time spent in the open arms by the duration of the trial $(10 \mathrm{~min})$.

NIH procedure. The task was conducted as described previously ${ }^{38}$. Briefly, mice received 3 consecutive days of training (days 1-3) prior to testing in a room with dim lighting to acclimate to the milk and the manner in which it is administered (metal nozzle). Training consisted of presenting the mice with a standard dualbearing sipper tube ( $5 \mathrm{oz}$. bottle) inserted between the wire bars of the home cage lid containing $90 \%$ sweetened condensed milk diluted in tap water. On day 4 , mice underwent home cage testing in which all mice were placed into a holding cage and then returned to the home cage one at a time for testing in dim lighting. The latency to drink was recorded over a 10-min period. Mice that did not approach the sipper bottle during the home cage test were excluded from the study (four mice in total). There were no baseline differences in latency to drink between groups in the home cage test. On day 5 , novel cage testing was conducted by placing a single mouse into a clean cage with no bedding of the same dimensions as their home cage, but under bright conditions and with a white piece of paper under the cage. Excess light was focused specifically on the sipper bottle. Mice were again presented with a sipper tube containing $90 \%$ sweetened milk, and the latency to drink over a 10 -min period was reported as a measure of anxiety-like behaviour.

c-Fos immunohistochemistry. All experiments were carried out at room temperature, as previously described ${ }^{38}$, unless otherwise specified. Ninety minutes after exposure to experimental factors, mice were sacrificed by intraperitoneal injection of Euthasol and perfused through the heart with $30 \mathrm{ml}$ of saline followed by $90 \mathrm{ml}$ of $4 \%$ paraformaldehyde in $0.1 \mathrm{M}$ sodium phosphate ( $\mathrm{pH} 7.4)$ at flow rate of $30 \mathrm{ml} \mathrm{min}-1$. Brains were removed and post-fixed overnight in $4 \%$ paraformaldehyde before being transferred to $30 \%$ sucrose in $0.1 \mathrm{M}$ sodium phosphate ( $\mathrm{pH} 7.4)$ for $48 \mathrm{~h}$ at $4{ }^{\circ} \mathrm{C}$. Brains were frozen in powdered dry ice and stored at $-20^{\circ} \mathrm{C}$ until sectioning. Coronal sections $(40 \mu \mathrm{m})$ of whole brain were cut by using sliding microtome frozen by powdered dry ice. Six sets of serial sections were collected in Ependoff tubes each containing $2 \mathrm{ml}$ cryoprotectant (30\% glycerol and $30 \%$ ethylene glycol in $0.1 \mathrm{M}$ sodium phosphate, $\mathrm{pH} 7.4$ ) and stored at $-20^{\circ} \mathrm{C}$. Free-floating serial sections (take one every third) were washed (three times for $10 \mathrm{~min}$ each) in TBS, incubated for $30 \mathrm{~min}$ in a blocking solution containing $4 \%$ normal horse serum and 1\% BSA in Tris buffered saline (TBS) with $0.2 \%$ Triton X-100 (TBS-Tx) and incubated overnight at $4{ }^{\circ} \mathrm{C}$ with rabbit anti-cFos primary antibody (c-Fos sc-52, Lot\# F2209, Santa Cruz Biotechnology, USA; sc-52 antibody was raised against amino acids 3-16 of human c-Fos: SGFNADYEASSSRC) diluted 1:1,000 mixed with goat anti-parvalbumin primary antibody (1:2,000, Lot\# PVG 214, Swant, Switzerland) in the blocking solution mentioned above. Sections were then washed in TBS and incubated for $2 \mathrm{~h}$ with Alexa Fluor-labelled donkey anti-rabbit and anti-goat IgG secondary antibodies (Alexa Fluor 555 and 488) diluted 1:500 in TBS-Tx. Sections were again washed, mounted on chromalum/gelatin-coated slides and air-dried for $2 \mathrm{~h}$ in dark. Slides were cover-slipped by water-soluble glycerol-based mounting medium containing 4',6-diamidino-2-phenylindole (DAPI), and sealed with nail polish. Estimation of cell density of c-Fos-positive neurons in amygdala was performed with StereoInvestigator 9.0 (Microbrightfield, USA). Briefly, serial sections (every third section $-120 \mu \mathrm{m}$ were numbered by rostra-caudal order, and contours of BLA was traced by referring to the Allen Brain Map (Allen Co., USA). For the boundaries of the amygdala, we used parvalbumin counter-stain combined with DAPI to yield a clear boundary for subnuclei or layers. All cells across all sections per animal were counted. Individual cell density was calculated for each mouse by dividing the total sampled cell numbers by the total volume of the region.

Stereotaxic injections of tracers. Mice were microinjected with $10 \mathrm{nl}$ of $4 \% \mathrm{FG}$ (Fluorochrome, USA) retrograde tracer in neutral saline or $50 \mathrm{nl}$ of AAV2-eGFP (cytomegalovirus (CMV) promoter, $5 \times 10^{11}$ VG per ml, Vector Biolabs, USA) into the PL (anterior-posterior $=1.9 \mathrm{~mm}$, medial-lateral $=0.4 \mathrm{~mm}$ and dorsalventral $=1.98 \mathrm{~mm}$ ) or IL (anterior-posterior $=2.0 \mathrm{~mm}$, medial-lateral $=0.3 \mathrm{~mm}$, dorsal-ventral $=2.0 \mathrm{~mm}$ ) PFC. Mice were anesthetized with an intraperitoneal injection of ketamine and xylazine cocktail at $0.1 \mathrm{ml}$ per $10 \mathrm{~g}$ body weight and mounted on a stereotaxic alignment system (David Kopf Instruments, USA). After surgical exposure of the skull, $3 \%$ of $\mathrm{H}_{2} \mathrm{O}_{2}$ solution was applied to enhance sutures and bregma. Stereotaxic coordination was performed using an electrical drill 
mounted on a manipulator (David Kopf Instruments) and microinjection was performed by Nanoject II (Drummond Scientific Nanoject II, Fisher Scientific, USA). Small deposits of FG or AAV2-eGFP tracers were pressure-injected three times over 2 min each into IL or PL using a glass micropipette (tip diameter $25 \mu \mathrm{m}$ ). The needle was left in place for additional $10 \mathrm{~min}$ to prevent leakage up the needle track and then slowly withdrawn.

Following a survival time of 7 days after FG injections or 10 days after AAV2-eGFP injections, animals were deeply anesthetized with Euthasol $0.1 \mathrm{ml}$ per $10 \mathrm{~g}$ body weight and perfused through the heart with $30 \mathrm{ml}$ of $0.9 \%$ saline followed by $120 \mathrm{ml}$ of cold $4 \%$ paraformaldehyde in a $0.01 \mathrm{M}$ sodium phosphate buffer $\left(25 \mathrm{ml} \mathrm{min}^{-1}\right)$ using the Perfusion Two automated pressure perfusion system (Leica Microsystems, USA). Brains were removed and post-fixed with $4 \%$ paraformaldehyde in a 0.01 -M sodium phosphate buffer at $4{ }^{\circ} \mathrm{C}$ overnight and then transferred to a sucrose solution ( $30 \%$ sucrose in $0.1 \mathrm{M}$ phosphate buffer at $4{ }^{\circ} \mathrm{C}$ for $48 \mathrm{~h}$. Coronal sections were cut on a freezing microtome $(40 \mu \mathrm{m})$. One section in every three was immediately mounted. The remaining sections were stored in cryoprotectant solution (30\% glycerol, $30 \%$ ethylene glycol and $40 \%$ $0.25 \mathrm{M} \mathrm{PB}$ ) at $-20^{\circ} \mathrm{C}$. The mounted sections were air-dried for at least $3 \mathrm{~h}$ and cover-slipped by using a FG-enhancing solution $\left(10 \% \mathrm{SiO}_{2}, 0.1 \mathrm{M}\right.$ Tris, $\left.\mathrm{pH} 11\right)$.

Injection sites were confirmed by referring to the Allen Mouse Brain Map (Allen Co.). Sections were observed under a Nikon 80i fluorescent microscope with a DAPI/FITC/Rhodamine Tri-colour filter. Digital photography was performed using a MicroFire camera and FireFrame software (Optronics, USA), and stereological estimation of cell density was performed using StereoInvestigator software (MicroBrightfeild, USA). Contours of the BLA were drawn and random sampling was applied to contours. Total volume of BLA was estimated using the Cavalieri method. Total cell numbers were estimated using a fractionator, with counting frame size $25 \times 25 \times 40 \mu \mathrm{m}$ and sampling grid size $100 \times 100 \mu \mathrm{m}$. Cell density was calculated by total cell number divided by total volume. Detection of fibre density was performed using a stereological method ${ }^{39}$. Briefly, sections were traced under a $\times 4$ lens and then perimetrics probe analysis was done under a $\times 40$ lens. Counting frame was set to $25 \times 25 \mu \mathrm{m}$ and radius of the Merz coherent test system was set to $5 \mu \mathrm{m}$. Total length of all sampling sites was automatically calculated. For each animal, fibre density is obtained from the sum of the lengths divided by the sum of the areas for all sections.

Human participants. All participants reported no past, present or first-degree family history of a psychiatric or neurologic disorder and no history of head trauma. Imaging participants were also all right-handed and pre-screened for magnetic resonance imaging (MRI) contraindications (for example, metal plates or implants and braces). All participants submitted written informed consent approved by the Institutional Review Board prior to the study. Compensation was provided as described in their written consent form. In total, 240 participants took part in this study. Each experiment was conducted on an independent cohort of subjects (Supplementary Tables 1-3).

Human genotyping. Human subjects provided saliva samples (Oragene, DNA Genotek Inc., Canada) from which we extracted genomic DNA according to the manufacturer's standard protocol. Genotyping for the FAAH C385A polymorphism ( $\mathrm{rs} 324420)$ was performed using a Taqman $5^{\prime}$ exonuclease assay (assay C__1897306_10, Applied Biosystems, USA) run on an Applied Biosystems 7900 HT real-time thermal cycler. Genotypes were called using Sequence Detection System software version 2.3. All samples that did not result in automated genotype calls were re-run in duplicate. and those samples that provided concordant genotypes called by visual inspection on re-run were used for analysis.

Image acquisition. All subject MRI data were collected with a Siemens MAGNETOM TrioTim MRI scanner (Siemens Medical Solutions, Germany). From each subject, we acquired a high-resolution, T1-weighted anatomical scan ( $256 \times 192$ in-plane resolution, $240 \mathrm{~mm}$ field of view, 1601.2 -mm slices) for normalization to a standard template ${ }^{40}$. Functional imaging data were pooled from multiple studies, resulting in slight differences in functional acquisition parameters. All functional data were collected using echo-planar imaging with interleaved acquisition. A representative example of specific acquisition parameters is: repetition time $(\mathrm{TR})=3,000 \mathrm{~ms}$ echo time $=30 \mathrm{~ms}$, field of view $=240 \mathrm{~mm}$, flip angle $=90^{\circ}, 46$ slices of $3.8 \times 3.8 \times 3.5 \mathrm{~mm}$ voxels. During each resting-state run, subjects were presented with a white visual fixation crosshair on a black background. They were asked to stay awake and refrain from movement during the task. Subjects completed either 1 run of 128 TRs or 2 runs of 150 TRs (see Imaging Data Preprocessing and Analysis showing similar genotypic effects regardless of number of acquisitions).

Imaging data preprocessing and analysis. All subjects' resting-state data underwent identical preprocessing steps. Imaging data were processed using Analysis of Functional Neuroimages software tools ${ }^{41}$. Scans were slice-time corrected for temporal alignment to this first slice of each volume. Calculations were then performed for rigid-body alignment of all functional volumes to the first series functional volume, rigid-body alignment of the subject's anatomical scan to their first functional volume and nonlinear transformation of the subject anatomical to the standard template. These three transformation matrices were combined and applied in a single step to minimize interpolation error. Functional scans were blurred to a target full-width at half-maximum of $4.0 \mathrm{~mm}$.

To minimize effects of motion on resting-state fMRI data, we followed recent recommendations for motion artefact correction ${ }^{42}$. Functional volumes exceeding a 0.2-mm framewise displacement, along with the preceding volume, were censored and excluded from all further preprocessing steps. A general linear model was used to compute the effects of 27 parameters: 6 motion parameters and their 6 first-derivatives, as well as average time courses from an eroded white-matter mask, an eroded grey-matter mask and the global signal. In addition, band-pass filtering $(0.01$ to $0.1 \mathrm{~Hz})$ and regression were applied concurrently on sub-motionthreshold TRs only to avoid reintroduction of noise from unfiltered regressors ${ }^{43}$. The error term of this general linear model was used for subsequent analysis.

We compared connectivity between a priori cortical areas of interest and the amygdala. First, time series were extracted from subgenual vmPFC and dorsal ACC seed regions of interest (ROIs). We drew 4-mm spherical ROIs around the centre of activation of these two brain regions areas, as defined in previous studies presenting convergent functional or structural evidence of a role for these regions in fear expression (dorsal ACC) or regulation (subgenual vmPFC) ${ }^{18,19}$. These seeds overlap with regions of activation correlating with fear regulation and expression from several other fear-conditioning studies ${ }^{44-46}$. A target ROI was constructed using a standard-based atlas, forming a bilateral mask of the amygdala. We calculated the mean correlation coefficient between each seed ROI and the target ROI. These values were Fischer-transformed and then compared between subject groupings based on the FAAH C385A genotype.

Due to the potential of temporal and frontal lobe signal dropout, we manually checked each subject for coverage of ROIs before including them in the final analysis. Only subjects with complete coverage of both seed ROIs and the target ROI were selected. We observed no volumetric structural differences between genotypic groups in either of our cortical ROIs (data not shown). These data were analysed including covariates of age, gender, ethnicity and number of resting-state scans. The main effect of genotype remained significant for subgenual vmPFC-amygdala connectivity $(\mathrm{F}(8,26)=4.88, P=0.036)$, and there was no effect of dorsal ACC-amygdala connectivity $(\mathrm{F}(8,26)=0.68, P=0.080)$.

Human fear-conditioning and extinction procedure. We utilized a 2-day fear-conditioning/-extinction paradigm. Acquisition occurred on experimental day 1 and extinction occurred $24 \mathrm{~h}$ later on experimental day 2 . Acquisition and extinction took place in different visual contexts consisting of pictures of rooms presented on the computer screen (contexts $\mathrm{A}$ and $\mathrm{B}^{47}$ ). Conditioned stimuli (CS) were two-coloured windows (blue and yellow) that were otherwise black, embedded within each visual context. The unconditioned stimulus (US) was a hybrid consisting of auditory and visual components. The visual component was derived from a set of validated aversive pictures from the International Affective Picture Series ${ }^{48}$. The auditory component was a validated custom-designed hybrid of white noise and a $1,000-\mathrm{Hz}$ tone with a duration of one second, intensity tiered for smooth onset and offset. It was created using the software Audacity 1.2.6 and was rated as aversive in multiple independent experiments (http:// audacity.sourceforge.net $)^{35,49,50}$. Fear acquisition took place in context A. One cue was paired with the US at a $50 \%$ reinforcement rate $(C S+)$. Each presentation of the US consisted of the same sound and a different picture. The other cue (CS - ) was never followed by the US. Participants were presented 32 trials during acquisition $(8 \mathrm{CS}+\mathrm{US}, 8 \mathrm{CS}+$ and $16 \mathrm{CS}-)$. After $24 \mathrm{~h}$ later, participants returned for experimental day 2 , which took place in context $\mathrm{B}$ and consisted of a 32-trial extinction session $(16 \mathrm{CS}+, 16 \mathrm{CS}-$ ). Stimuli were presented in a pseudorandomized order, defined by non-consecutive CS + USs during conditioning and no more than three consecutive squares of

the same colour in any session. Visual contexts, stimuli and script orders were counterbalanced across subjects. Fear response was measured by skin conductance response (SCR), an index of autonomic nervous system activity ${ }^{51}$. Differential fear responding was calculated by subtracting normalized and scaled SCR to the CS - from corresponding CS + responses. Only subjects who showed fear acquisition (magnitude of SCR to the CS + was greater than to the CS - during acquisition) were included in the analyses.

In this experiment, half the participants were randomly assigned to either a reconsolidation update or extinction-only condition. Participants who were assigned to the reconsolidation update condition received a single presentation of the CS +, unpaired with the aversive stimulus, prior to a 10 - min rest period followed immediately by the extinction session. Controlling for the effects of this experimental condition together with age, sex and ethnicity results in a similar main effect of genotype for late trials $(\mathrm{F}(1,32)=3.09, P<0.09)$. Genotypic differences in fear extinction learning diminished with five additional extinction trials (main effect of genotype: $(\mathrm{F}(1,32)=0.04, P=0.83$, CC: $-0.031 \pm 0.028$; AC/AA: $-0.044 \pm 0.028)$.

Physiological response measurement and analysis. Throughout fear conditioning and extinction, participant SCR was recorded via disposable electrodes attached to the distal phalanx of the second and third digits of the left hand. Electrodes came pre-filled with isotonic gel. All stimuli were presented using E-prime software (Psychology Software Tools, USA). This software sent time 
markers to the skin conductance recording system (MP35; Biopac, USA), which recorded and amplified SCR in combination with AcqKnowledge software (Biopac).

SCR was recorded at a sampling frequency of $200 \mathrm{~Hz}$ with a $1-\mathrm{Hz}$ filter and manually smoothed. After each stimulus presentation, the first SCR peak occurring within $0.5-4.5 \mathrm{~s}$ was considered the subject's response to that stimulus. Responses, as estimated by the difference between trough and peak, were only included in analysis when $>0.02 \mu S^{52}$. Responses smaller than this threshold were replaced with zeros during analysis. During analysis, individual SCR responses were squareroot-transformed and scaled to that participant's largest CS + US acquisition response. Normalized SCR scores were averaged separately by stimulus type $(\mathrm{CS}+, \mathrm{CS}-$ and CS + US). All presented responses were calculated as the difference between $\mathrm{CS}+$ and $\mathrm{CS}-$ responses.

Anxiety self-report. A subset of participants (Supplementary Table 3) completed the State Trait Anxiety Inventory (STAI-S; STAI-T) self-report questionnaires separately assessing current and general levels of anxiety ${ }^{53}$. These results remained significant after co-varying the effects of age, sex and ethnicity (main effect of genotype: $\mathrm{F}(7,129)=5.22, P<0.024)$.

Statistics. When two groups were compared, data were analysed using a Student's $t$-test. For multiple comparisons, a one-way ANOVA followed by Dunnett's post hoc test or a two-way ANOVA followed by Bonferroni post hoc test was used. A value of $P \leq 0.05$ was considered to be statistically significant.

Alternative statistical analyses. To examine the robustness of the human findings given uncertainty about the true distribution of this data, we tested our main hypotheses using a Bayesian statistical framework. Statistical analysis was performed within the R statistical software package, version 2.15.1 ${ }^{54}$. Bayesian statistical analyses were implemented using the 'Bayesian estimation' (BEST) software package for $\mathrm{R}^{55}$.

STAI replication analysis. We examined the effect of the rs324420 allele in our fear extinction cohort to determine whether this behavioural genetic finding was replicable. We examined the correlation between number of mutant C385A alleles and normalized STAI-trait anxiety scores.

\section{References}

1. Hariri, A. R. et al. Divergent effects of genetic variation in endocannabinoid signaling on human threat- and reward-related brain function. Biol. Psychiatry 66, 9-16 (2009)

2. Gunduz-Cinar, O. et al. Convergent translational evidence of a role for anandamide in amygdala-mediated fear extinction, threat processing and stress-reactivity. Mol. Psychiatry 18, 813-823 (2013).

3. Hill, M. N., Miller, G. E., Ho, W. S., Gorzalka, B. B. \& Hillard, C. J. Serum endocannabinoid content is altered in females with depressive disorders: a preliminary report. Pharmacopsychiatry 41, 48-53 (2008).

4. Gunduz-Cinar, O., Hill, M. N., McEwen, B. S. \& Holmes, A. Amygdala FAAH and anandamide: mediating protection and recovery from stress. Trends Pharmacol. Sci. 34, 637-644 (2013).

5. Cravatt, B. F. et al. Supersensitivity to anandamide and enhanced endogenous cannabinoid signaling in mice lacking fatty acid amide hydrolase. Proc. Natl Acad. Sci. USA 98, 9371-9376 (2001).

6. Abecasis, G. R. et al. An integrated map of genetic variation from 1,092 human genomes. Nature 491, 56-65 (2012).

7. Sipe, J. C., Chiang, K., Gerber, A. L., Beutler, E. \& Cravatt, B. F. A missense mutation in human fatty acid amide hydrolase associated with problem drug use. Proc. Natl Acad. Sci. USA 99, 8394-8399 (2002).

8. Sipe, J. C. et al. Biomarkers of endocannabinoid system activation in severe obesity. PLoS ONE 5, e8792 (2010).

9. Chiang, K. P., Gerber, A. L., Sipe, J. C. \& Cravatt, B. F. Reduced cellular expression and activity of the P129T mutant of human fatty acid amide hydrolase: evidence for a link between defects in the endocannabinoid system and problem drug use. Hum. Mol. Genet. 13, 2113-2119 (2004).

10. Kathuria, S. et al. Modulation of anxiety through blockade of anandamide hydrolysis. Nat. Med. 9, 76-81 (2003).

11. Chhatwal, J. P., Davis, M., Maguschak, K. A. \& Ressler, K. J. Enhancing cannabinoid neurotransmission augments the extinction of conditioned fear. Neuropsychopharmacology 30, 516-524 (2005).

12. Vidal-Gonzalez, I., Vidal-Gonzalez, B., Rauch, S. L. \& Quirk, G. J. Microstimulation reveals opposing influences of prelimbic and infralimbic cortex on the expression of conditioned fear. Learn. Mem. 13, 728-733 (2006).

13. Laurent, V. \& Westbrook, R. F. Inactivation of the infralimbic but not the prelimbic cortex impairs consolidation and retrieval of fear extinction. Learn. Mem. 16, 520-529 (2009).

14. Sierra-Mercado, D., Padilla-Coreano, N. \& Quirk, G. J. Dissociable roles of prelimbic and infralimbic cortices, ventral hippocampus, and basolateral amygdala in the expression and extinction of conditioned fear. Neuropsychopharmacology 36, 529-538 (2011).

15. Phelps, E. A. \& LeDoux, J. E. Contributions of the amygdala to emotion processing: from animal models to human behavior. Neuron 48, 175-187 (2005).

16. Hartley, C. A. \& Phelps, E. A. Changing fear: the neurocircuitry of emotion regulation. Neuropsychopharmacology 35, 136-146 (2010).

17. Phelps, E. A., Delgado, M. R., Nearing, K. I. \& LeDoux, J. E. Extinction learning in humans: role of the amygdala and vmPFC. Neuron 43, 897-905 (2004).

18. Milad, M. R. et al. A role for the human dorsal anterior cingulate cortex in fear expression. Biol. Psychiatry 62, 1191-1194 (2007).

19. Schiller, D. \& Delgado, M. R. Overlapping neural systems mediating extinction, reversal and regulation of fear. Trends Cogn. Sci. 14, 268-276 (2010).

20. Kim, H. et al. Contextual modulation of amygdala responsivity to surprised faces. J. Cogn. Neurosci. 16, 1730-1745 (2004).

21. Urry, H. L. et al. Amygdala and ventromedial prefrontal cortex are inversely coupled during regulation of negative affect and predict the diurnal pattern of cortisol secretion among older adults. J. Neurosci. 26, 4415-4425 (2006).

22. Hare, T. A. et al. Biological substrates of emotional reactivity and regulation in adolescence during an emotional go-nogo task. Biol. Psychiatry 63, 927-934 (2008).

23. Kim, M. J., Gee, D. G., Loucks, R. A., Davis, F. C. \& Whalen, P. J. Anxiety dissociates dorsal and ventral medial prefrontal cortex functional connectivity with the amygdala at rest. Cereb. Cortex 21, 1667-1673 (2011).

24. Burghy, C. A. et al. Developmental pathways to amygdala-prefrontal function and internalizing symptoms in adolescence. Nat. Neurosci. 15, 1736-1741 (2012).

25. Hahn, A. et al. Reduced resting-state functional connectivity between amygdala and orbitofrontal cortex in social anxiety disorder. Neuroimage 56, 881-889 (2011).

26. Kim, M. J. et al. The structural and functional connectivity of the amygdala: from normal emotion to pathological anxiety. Behav. Brain Res. 223, 403-410 (2011).

27. Moreira, F. A., Kaiser, N., Monory, K. \& Lutz, B. Reduced anxiety-like behaviour induced by genetic and pharmacological inhibition of the endocannabinoid-degrading enzyme fatty acid amide hydrolase (FAAH) is mediated by CB1 receptors. Neuropharmacology 54, 141-150 (2008).

28. Chhatwal, J. P. \& Ressler, K. J. Modulation of fear and anxiety by the endogenous cannabinoid system. CNS Spectr. 12, 211-220 (2007).

29. Conzelmann, A. et al. A polymorphism in the gene of the endocannabinoiddegrading enzyme FAAH (FAAH C385A) is associated with emotionalmotivational reactivity. Psychopharmacology (Berl) 224, 573-579 (2012).

30. Dulawa, S. C. \& Hen, R. Recent advances in animal models of chronic antidepressant effects: the novelty-induced hypophagia test. Neurosci. Biobehav. Rev. 29, 771-783 (2005).

31. Dragunow, M. \& Faull, R. The use of c-fos as a metabolic marker in neuronal pathway tracing. J. Neurosci. Methods 29, 261-265 (1989).

32. Yang, J. et al. Neuronal release of proBDNF. Nat. Neurosci. 12, 113-115 (2009)

33. Lee, T. T., Hill, M. N., Hillard, C. J. \& Gorzalka, B. B. Temporal changes in $\mathrm{N}$-acylethanolamine content and metabolism throughout the peri-adolescent period. Synapse 67, 4-10 (2013).

34. Lee, T. T. \& Hill, M. N. Age of stress exposure modulates the immediate and sustained effects of repeated stress on corticolimbic cannabinoid $\mathrm{CB}(1)$ receptor binding in male rats. Neuroscience 249, 106-114 (2013).

35. Pattwell, S. S. et al. Altered fear learning across development in both mouse and human. Proc. Natl Acad. Sci. USA 109, 16318-16323 (2012).

36. Fanselow, M. S. Conditioned and unconditional components of post-shock freezing. Pavlov. J. Biol. Sci. 15, 177-182 (1980).

37. Chen, Z. Y. et al. Genetic variant BDNF (Val66Met) polymorphism alters anxiety-related behavior. Science 314, 140-143 (2006).

38. Malter Cohen, M. et al. Early-life stress has persistent effects on amygdala function and development in mice and humans. Proc. Natl Acad. Sci. USA 110, 18274-18278 (2013).

39. Howard, C. V. \& Reed, M. G. Unbiased Stereology (Garland Science, 2005).

40. Talairach, J. \& Tournoux, P. Co-Planar Stereotaxic Atlas of the Human Brain 3-Dimensional Proportional System: an Approach to Cerebral Imaging (Georg Thieme, 1988).

41. Cox, R. W. AFNI: software for analysis and visualization of functional magnetic resonance neuroimages. Comput. Biomed. Res. 29, 162-173 (1996).

42. Power, J. D. et al. Methods to detect, characterize, and remove motion artifact in resting state fMRI. Neuroimage 84, 320-341 (2014).

43. Hallquist, M. N., Hwang, K. \& Luna, B. The nuisance of nuisance regression: spectral misspecification in a common approach to resting-state fMRI preprocessing reintroduces noise and obscures functional connectivity. Neuroimage 82, 208-225 (2013).

44. Etkin, A., Egner, T. \& Kalisch, R. Emotional processing in anterior cingulate and medial prefrontal cortex. Trends Cogn. Sci. 15, 85-93 (2011). 
45. Mechias, M. L., Etkin, A. \& Kalisch, R. A meta-analysis of instructed fear studies: implications for conscious appraisal of threat. Neuroimage 49, 1760-1768 (2010)

46. Klucken, T. et al. Neural, electrodermal and behavioral response patterns in contingency aware and unaware subjects during a picture-picture conditioning paradigm. Neuroscience 158, 721-731 (2009).

47. Milad, M. R., Orr, S. P., Pitman, R. K. \& Rauch, S. L. Context modulation of memory for fear extinction in humans. Psychophysiology 42, 456-464 (2005).

48. Lang, P. J. International Affective Picture System (IAPS): Affective Ratings of Pictures and Instruction Manual (University of Florida, 2005).

49. Soliman, F. et al. A genetic variant BDNF polymorphism alters extinction learning in both mouse and human. Science 327, 863-866 (2010).

50. Levita, L. et al. The bivalent side of the nucleus accumbens. Neuroimage 44, 1178-1187 (2009).

51. LaBar, K. S., Gatenby, J. C., Gore, J. C., LeDoux, J. E. \& Phelps, E. A. Human amygdala activation during conditioned fear acquisition and extinction: a mixed-trial fMRI study. Neuron 20, 937-945 (1998).

52. Schiller, D. et al. Preventing the return of fear in humans using reconsolidation update mechanisms. Nature 463, 49-53 (2010).

53. CD S. STAI: manual for the State Trait Anxiety Inventory, 3rd edn (Consulting Psychologists Press, 1988).

54. R Core Team. R: a language and environment for statistical computing. R Foundation for Statistical Computing http://www.R-project.org/ (2012).

55. Kruschke, J. K. BEST: Bayesian estimation supersedes the t-test http://CRAN. R-project.org/package=BEST (2013).

\section{Acknowledgements}

We acknowledge the resources and staff at the Biomedical Imaging Core Facility of the Citigroup Biomedical Imaging Centre at Weill Cornell Medical College, a generous gift by the Dr Mortimer D. Sackler family. We acknowledge support from NIH grants MH079513 (B.J.C., F.S.L. and C.E.G.), MH060478 (B.J.C.), NS052819 (F.S.L.), GM07739 (A.T.D.), EY007138 (D.C.J), DA017259 (B.F.C.), and the Pritzker Neuropsychiatric Disorders Research Consortium (F.S.L. and C.E.G.), the NewYorkPresbyterian Hospital Youth Anxiety Centre (F.S.L. and B.J.C.), Brain and Behavior Research Foundation (F.S.L. and D.J.), DeWitt-Wallace Fund of the New York Community Trust (F.S.L., B.J.C. and C.E.G.) and the Canadian Institutes of Health Research (M.N.H.) and Alberta Innovates Health Solutions (J.M.G.). We would also like to acknowledge the Southern Alberta Mass Spectrometry Centre, located in and supported by the Cumming School of Medicine, University of Calgary for their services in targeted LC-MS/MS. We acknowledge Dr Jack Barchas for extensive discussions on the design and implementation of these studies.

\section{Author contributions}

I.D. collected and analysed mouse extinction data and was involved in manuscript preparation. A.T.D. and C.A.H. collected and analysed human neuroimaging and anxiety data and were involved in study design and manuscript preparation. D.C.J. collected and analysed human extinction data. D.J. performed stereotaxic injections and along with R.Y. performed immunohistochemitry studies. E.C.K. performed western blot analysis and along with S.R. collected mouse anxiety data. A.M.D. generated the FAAH mouse knock-in line. J.M.G. and M.N.H. performed enzymatic activity, endocannabinoid content and receptor-binding assays. B.F.C. provided the FAAH $^{-1-}$ mouse line, and was involved in study design. M.N.H. was also involved in study design and manuscript preparation. C.H. maintained mouse colony and genotyping. C.E.G. performed human genotyping and was involved in manuscript preparation. B.J.C. and F.S.L. designed the study and were involved in data analysis and manuscript preparation. All authors discussed the results and contents of the manuscript.

\section{Additional information}

Supplementary Information accompanies this paper at http://www.nature.com/ naturecommunications

Competing financial interests: M.N.H. is a consultant for Pfizer. The remaining authors declare no competing financial interests.

Reprints and permission information is available online at http://npg.nature.com/ reprintsandpermissions/

How to cite this article: Dincheva, I. et al. FAAH genetic variation enhances fronto-amygdala function in mouse and human. Nat. Commun. 6:6395 doi: 10.1038/ncomms7395 (2015) 